\title{
Carbon dioxide capture using various metal oxyhydroxide-biochar composites
}

\author{
Anne Elise Creamer, Bin Gao*, Shengsen Wang
}

Department of Agricultural and Biological Engineering, University of Florida, Gainesville, FL32611

*Corresponding author, phone: (352) 392-1864 ext.285, email: bg55@ufl.edu 


\begin{abstract}
Innovative and cost-effective methods are needed to capture and store $\mathrm{CO}_{2}$ to reduce anthropogenic impact on global warming. This work produced and characterized aluminum hydroxide, magnesium hydroxide, and iron oxide-biochar composites, and evaluated their ability to capture $\mathrm{CO}_{2}$ at room temperature and atmospheric pressure. Biomass feedstocks were treated with metal ions of a variety of concentrations, and were then pyrolyzed at $600{ }^{\circ} \mathrm{C}$. Characterization experiments showed that the process not only turned the biomass into biochar, but also converted the metal ions into metal oxyhydroxide nanoparticles onto the carbon surfaces with the biochar matrix. As a result, the composites, particularly the ones with optimal metal to biomass ratios, had higher $\mathrm{CO}_{2}$ capture capacity than the unmodified biochar. All the composites had relatively large surface area and captured $\mathrm{CO}_{2}$ mainly through physical adsorption. Although $\mathrm{Fe}_{2} \mathrm{O}_{3}$-biochar composites had the highest surface area, the AlOOH-biochar composite showed the largest sorption. Thus, both the characteristics of the metal oxyhydroxides and the surface area contributed to the $\mathrm{CO}_{2}$ capture capacity. The maximum adsorption capacity $\left(71 \mathrm{mg} \mathrm{g}^{-1}\right.$ at $\left.25^{\circ} \mathrm{C}\right)$ by $\mathrm{AlOOH}$-biochar is comparable to commercial adsorbents. The samples had between $90-99 \%$ desorption at $120{ }^{\circ} \mathrm{C}$, so they required low cost regeneration. All these results suggested that biochar-based composites could be a high efficiency and cost-effective adsorbent for $\mathrm{CO}_{2}$ capture.
\end{abstract}

Keywords: engineered biochar; biochar nanocomposites; $\mathrm{CO}_{2}$ capture; $\mathrm{CO}_{2}$ adsorption; carbon sequestration 


\section{Introduction}

As a greenhouse gas, carbon dioxide $\left(\mathrm{CO}_{2}\right)$ is one of the major contributors to global warming and is significantly produced from anthropogenic sources. To reduce greenhouse gas emission, $\mathrm{CO}_{2}$ capture technologies are retrofitted to power plants post combustion in the electric-power sector [1]. Unfortunately, current $\mathrm{CO}_{2}$ capture technologies have high energy penalties [2] and the most robust technology, amine scrubbing [3], has significant negative human and environmental drawbacks [4]. It is therefore necessary to develop effective $\mathrm{CO}_{2}$ sorbents that are inexpensive and renewable, for use in large-scale post combustion technologies.

Physical adsorbents, such as carbon materials, have potential to capture $\mathrm{CO}_{2}$ with higher stability, higher regeneration, and lower energy consumption than conventional chemical processes [5-7]. Many of the adsorbents for $\mathrm{CO}_{2}$ capture, however, are relatively high priced and thus, there are needs for the development of cost-effective ones. Biochar is a low-cost carbon material that can be produced by low temperature pyrolysis of waste biomass [8-10]. Biochar is often used as soil amendment for soil improvement and carbon sequestration [11-13]. Recently, Creamer et al. [14] showed that biochar has the ability to capture $\mathrm{CO}_{2}$ at levels comparable to well-established adsorbents. In comparison to other commonly used $\mathrm{CO}_{2}$ capture adsorbents, biochar is more cost-effective because of following advantages: (1) it can be produced from waste organic materials; (2) its production is performed at relatively low temperature; (3) the material can also be regenerated at a low energy, due to its physical adsorption behavior [14]. 
Recent development of the biochar technology showed that biochars can be modified (i.e., engineered biochars) to enhance their sorption ability to various chemical compounds [15-17]. Previous studies have used metal oxyhydroxide-biochar composites to capture contaminants in aqueous solutions. For example, Zhang et al. [18] used MgObiochar composite to remove phosphate and nitrate from solution. Yao et al. [19] used Mg oxyhydroxide biochar to remove phosphate in solution. In both studies, there was a strong correlation between the $\mathrm{Mg}$ content and the removal P from solution, which can be explained by the electrostatic interactions between the $\mathrm{P}$ and the $\mathrm{Mg}$ oxyhydroxide particles on biochar surfaces. Zhang and Gao [20] used a AlOOH /biochar composite to successfully remove arsenic and methylene blue from solution. In this case, the aluminum in biochar served as a precursor for the formation of $\mathrm{AlOOH}$ nanoparticles, which increased bonding affinity of the sorbent to the contaminants. Similarly, an $\mathrm{AlOOH}$ and mesoporous carbon composite was synthesized in a study by Chang et al. [21]; this stable framework had high surface area and showed to be capable of rapid $\mathrm{CO}_{2}$ capture. Other metal oxyhydroxide-biochar composites, such as $\mathrm{Fe}_{2} \mathrm{O}_{3}$-biochar composite, which possessed ferromagnetic properties due to the presence of iron oxide [22, 23], have also been synthesized and showed enhanced sorption to various contaminants.

Previous studies have shown that frameworks with open metal sites tend to have a high affinity for $\mathrm{CO}_{2}[5]$. The basic nature of carbon and metal oxide frameworks enhances the selectivity of the material toward $\mathrm{CO}_{2}$ over $\mathrm{CH}_{4}$ and $\mathrm{N}_{2}$, two other components in flue gas. Further, the addition of polar basic groups produces a reversible bond with $\mathrm{CO}_{2}$ [5]. Metal oxyhydroxides are generally basic, so tend to bond with $\mathrm{CO}_{2}$, an acidic gas, when polar surfaces are in contact. It is thus expected that the biochar- 
based composites should also capture $\mathrm{CO}_{2}$. Nevertheless, only few studies have investigated the sorption of $\mathrm{CO}_{2}$ on metal oxyhydroxide-biochar composites [24].

The overarching objective of this work was to determine the effectiveness of metal oxyhydroxide-biochar composites for the capture of $\mathrm{CO}_{2}$. Specifically, this research aimed to 1) produce and characterize metal oxyhydroxide-biochar composites of three metals(aluminum, iron, and magnesium); 2) assess and model $\mathrm{CO}_{2}$ capture kinetics onto the composites; 3 ) optimize the production of the composites for $\mathrm{CO}_{2}$ capture; and 4) recognize the governing mechanisms for $\mathrm{CO}_{2}$ sorption onto the composites.

\section{Experimental}

\subsection{Materials}

Cottonwood $(\mathrm{CW})$ trees are commonly found in the southern regions of the United States. For this study, raw cottonwood feedstock was obtained from Gainesville, FL and was then dried and milled into $\sim 2 \mathrm{~mm}$ fractions. Three metal salts, aluminum chloride, iron chloride, and magnesium chloride hexahydrate were purchased from Carolina Biologicals.

\subsection{Biochar/metal oxyhydroxide composite production}

The biochar-based composites were produced using procedures suggested in previous studies [18, 20,22], which all produced large quantities of biochar/metal oxyhydroxide composites using one-step pyrolysis. Varying amounts of $\mathrm{AlCl}_{3}, \mathrm{FeCl}_{3}$, and $\mathrm{MgCl}_{2}$ hexahydrate were dissolved in solution with $60 \mathrm{~mL}$ of deionized (DI) water. 5 grams of cottonwood was mixed into the solution and stirred until it was saturated. The 
mixture was dried completely at $60{ }^{\circ} \mathrm{C}$ and then pyrolyzed at $600{ }^{\circ} \mathrm{C}$ in a tube furnace under nitrogen flow for 3 hours. The resulting biochars were then rinsed with tap water for 40 minutes and rinsed with DI water for 20 minutes to remove excess metal and impurities. The biochar samples were then dried, and stored in sealed containers. The samples were labeled by abbreviations representing the metal and feedstock: AlCW (aluminum and cottonwood), $\mathrm{MgCW}$ (magnesium and cottonwood), $\mathrm{FeCW}$ (iron and cottonwood). The unmodified cottonwood biochar was labeled as $\mathrm{CW}(0)$.

\subsection{Properties of biochar/metal oxyhydroxide composites}

All the biochar samples were characterized for surface area, pore volume, crystal structure, metal content, and material structure. Surface area analysis was performed with a Quantachrome Autosorb-1 analyzer using the $\mathrm{N}_{2}$ adsorption method. To qualitatively approximate the size of particles, SEM analysis was performed at 8,000x and 5,000x magnification. Once the particles on the surface of the composite are detected, EDS (Energy Dispersive X-ray spectroscopy) at 1000x magnification was used to confirm that these particles are metal compounds. In order to classify the crystalline forms of the metal oxyhydroxides on the samples, X-ray diffraction (XRD) analysis was performed using a computer-controlled X-ray diffractometer. XRD data along with the Scherrer method was used to further calculate particle size. The concentration of metals (aluminum, iron, and magnesium) in the biochar was determined with the AOAC method using inductively coupled plasma with atomic emission spectroscopy (ICP-AES, Perkin Elmer Optima 2100 DV). 


\section{4. $\mathrm{CO}_{2}$ capture}

Adsorption kinetic measurements were performed with a Thermogravimetric Analysis (TGA) instrument at a flow rate of $50 \mathrm{~mL} / \mathrm{min}$ following the procedures of Shafeeyan, Daud, Houshmand and Arami-Niya [25]. Because $\mathrm{CO}_{2}$ capture is most effective under high flow conditions [26], this low flow rate may underestimate the total adsorption capacity of the biochar for $\mathrm{CO}_{2}$. About $20 \mathrm{mg}$ of sample was placed on the TGA balance. Nitrogen gas was first used to purge potential volatile components out of the sample and chamber at $120^{\circ} \mathrm{C}$ at $50 \mathrm{~mL} / \mathrm{min}$. The temperature was then lowered to 25 ${ }^{\circ} \mathrm{C}$ and $\mathrm{CO}_{2}$ flows through at a rate of $50 \mathrm{~mL} / \mathrm{min}$ for 3 hours. Baseline mass measurements were taken once $\mathrm{CO}_{2}$ starts to flow through the TGA. To mitigate instrument and buoyancy influences, a blank run was performed under identical test conditions. The $\mathrm{CO}_{2}$ adsorption kinetic measurements for each of the 21 samples were measured by TGA and the results are modeled using a $2^{\text {nd }}$ order adsorption kinetic model.

\subsection{Regeneration}

For selected biochar samples, after the $\mathrm{CO}_{2}$ passed through the TGA at $25^{\circ} \mathrm{C}$ for 3 hours, the gas switched to $\mathrm{N}_{2}$, and the temperature was elevated to $120{ }^{\circ} \mathrm{C}$ again for 3 hours. The remaining mass of $\mathrm{CO}_{2}$ was divided by the mass of $\mathrm{CO}_{2}$ captured after 3 hrs at $25{ }^{\circ} \mathrm{C}$ to calculate the efficiency of regeneration.

\section{Results and Discussion}

\subsection{Biochar Characterization}


Due to the nature of biochar, the samples were highly carbonaceous. When the feedstock was modified with the salt $\left(\mathrm{AlCl}_{3}, \mathrm{MgCl}_{2}\right.$, or $\left.\mathrm{FeCl}_{3}\right)$, the concentration of each respective metal increased (Table 1), indicating the metals were successfully loaded into the biochar. For the biomass treated with $\mathrm{MgCl}_{2}$, the percent of metal in the compound ranged from $<0.1 \%$ in the unmodified cottonwood biochar to $5.74 \%$ in $\mathrm{MgCW}(40)$, which had a solution mixture ratio of $40: 1\left(\mathrm{MgCl}_{2} \cdot 6 \mathrm{H}_{2} \mathrm{O}: \mathrm{H}_{2} \mathrm{O}\right)$. The surface area ranged from $99 \mathrm{~m}^{2} / \mathrm{g}$ to $290 \mathrm{~m}^{2} / \mathrm{g}$ in $\mathrm{MgCW}(20)$. There was no significant correlation between the concentration of magnesium metal in the $\mathrm{MgCW}$ samples to the surface area $\left(\mathrm{r}^{2}=0.22\right)$ nor the pore volume $\left(\mathrm{r}^{2}=0.27\right)$.

For $\mathrm{FeCW}$, the surface area of the metal biochar composite ranged from $99 \mathrm{~m}^{2} / \mathrm{g}$ in the unmodified cottonwood biochar to $750 \mathrm{~m}^{2} / \mathrm{g}$ in $\mathrm{FeCW}(10)$, which had the highest concentration of iron. The percent of iron in the biochar ranged from $<0.1$ in $\mathrm{CW}(0)$ to $3.7 \%$ in $\mathrm{FeCW}(10)$. The pore volume was also highest $\left(.39 \mathrm{~cm}^{3} / \mathrm{g}\right)$ in $\mathrm{FeCW}(10)$. The correlation between the iron concentration and surface area in the $\mathrm{FeCW}$ samples was high $\left(\mathrm{r}^{2}=0.87\right)$ and the correlation with pore volume was slightly lower $\left(\mathrm{r}^{2}=0.77\right)$.

The percent of metal in the compound ranges from $<0.1 \%$ in the unmodified cottonwood to $0.8 \%$ in the aluminum sample that had a ratio of $4: 1\left(\mathrm{AlCl}_{3} \cdot \mathrm{H}_{2} \mathrm{O}\right)$. There was a relatively high correlation between the metal ratio in solution and the surface area of AlCW samples $\left(\mathrm{r}^{2}=0.78\right)$. As the concentration of metal in the solution increases, the surface area tended to increase, although there were only small amounts of aluminum in the composite. The highest surface area was attributed to the samples with highest concentration of aluminum in solution. AlCW(3) delivered a value of $370 \mathrm{~m}^{2} / \mathrm{g}$ and similarly, AlCW(4) had a surface area of $367 \mathrm{~m}^{2} / \mathrm{g}$. There was a low correlation between 
the percent of aluminum in $\mathrm{AlCW}$ biochar metal composite and the surface area $\left(r^{2}=0.37\right)$, as well as with the with pore volume $\left(0.47 \mathrm{~m}^{2} / \mathrm{g}\right)$.

SEM images show that the MgCW sample was made up of few oblong particles, perhaps carbon, which are decorated with particles of varying size; some particles had dimensions of less than 100nm (Figure S1, Supporting Information). Mono-dispersed particles with sizes less than 100nm were also found on the surface of the FeCW. The morphology of the AlCW sample appeared euhedral, with an angular stacking morphology. In order to determine whether the particles were composed of metal compounds, EDS was used at 1000x magnification. Figure 1 shows the location on the SEM image where the EDS data were taken. The imaging makes it possible to identify iron oxide particles on the surface of the carbon framework (Figure 1c). In Figure 1a, $\mathrm{Mg}(\mathrm{OH})_{2}$ particles can be seen on the surface of the carbon framework. Boehmite particles can be seen on the surface of the carbon framework (Figure 1b). EDS elemental analysis confirmed that the presence of iron, magnesium, and aluminum in each representative $\mathrm{FeCW}, \mathrm{MgCW}$, and $\mathrm{AlCW}$ sample, was much higher than that of the unmodified (CW) sample (Figure 1a, 1b, and 1c).

XRD testing was used to determine the crystalinity and type of metal oxyhydroxides present in the samples. FeCW and $\mathrm{MgCW}$ samples had the strongest

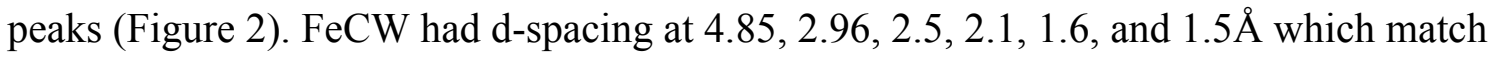
the iron oxide $\left(\mathrm{Fe}_{2} \mathrm{O}_{3}\right)$ diffraction patterns in the literature [27]. $\mathrm{MgCW}$ had the diffraction d-spacing at $4.8,2.7,2.4,1.8$, and $1.6 \AA$, which match the reported diffraction patterns for Brucite $\left(\mathrm{Mg}(\mathrm{OH})_{2}\right)$ [27]. AlCW had d-spacing at 6.2, 2.3, 1.9, and 1.4 $\AA$, which match the reported diffraction patterns for Boehmite (AlOOH) [27]. As observed 
by their well-defined peaks, the metal oxyhydroxide particles on $\mathrm{MgCW}$ and $\mathrm{FeCW}$ samples were highly crystalline.

In this work, the pyrolysis of $\mathrm{MgCl}_{2}$ treated biomass introduced $\mathrm{Mg}(\mathrm{OH})_{2}$ particles on the biochar, which is unlike the results of Zhang et a. [18] that indicate the presence of $\mathrm{MgO}$ particles on the biochar surface. The discrepancy might due to differences in the pyrolysis and rinsing processes. In particular, the rinsing of the samples in this study was much more intense and with higher volume of water, which leads to the conversion of $\mathrm{MgO}$ into $\mathrm{Mg}(\mathrm{OH})_{2}$. Yao et al. $[19,28]$ observed both $\mathrm{MgO}$ and $\mathrm{Mg}(\mathrm{OH})_{2}$ particles on biochar surfaces after pyrolyzing Mg-enriched feedstocks. The presences of $\mathrm{AlOOH}$ and $\mathrm{Fe}_{2} \mathrm{O}_{3}$ particles on the $\mathrm{AlCW}$ and $\mathrm{FeCW}$ samples are analogous to the results obtained in previous studies [20,22], probably because these two metal oxyhydroxides are more stable than the $\mathrm{MgO}$ when they are in contact with water. Because SEM revealed the presence of particles in the nano range for all samples (Figure S1, Supporting Information), the Scherrer formula was used to further approximate the size. The representative $\mathrm{MgCW}, \mathrm{FeCW}$, and $\mathrm{AlCW}$ samples had particle sizes of about $23 \mathrm{~nm}$, $36 \mathrm{~nm}$, and $3 \mathrm{~nm}$, respectively, which is similar to the findings of previous studies [18-20, $22,28]$.

The characterization results showed that the synthesis method used in this work successfully produced iron, aluminum, and magnesium oxyhydroxide-biochar composites at a variety of metal concentrations and with extensive surface area. Depending on the needs, these biochar-based composites may be used as adsorbents for various applications. 


\section{2. $\mathrm{CO}_{2}$ capture kinetics}

Figure 3(a, b, and c) illustrates the capture kinetic curve for each of the optimal metal concentrations in the metal-biochar composites (i.e., had the highest $\mathrm{CO}_{2}$ capture of its kind) and show that the amount of $\mathrm{CO}_{2}$ captured tends to level off after 30 minutes. The sorption kinetics of all the biochar samples were fitted with the second order kinetics model that followed the procedures of Creamer et al. [14]. Table 2 gives the best-fit parameters for the model along with the correlation coefficient $\left(R^{2}\right)$. The values for the equilibrium amount of the adsorbed $\mathrm{CO}_{2}\left(q_{e}\right)$ ranged from 27 to $63 \mathrm{mg} \mathrm{g}^{-1}$ for $\mathrm{MgCW}, 54$ to $67 \mathrm{mg} \mathrm{g}^{-1}$ for FeCW, and 63 to $71 \mathrm{mg} \mathrm{g}^{-1}$ for AlCW. Unmodified cottonwood biochar has a $q_{e}$ of $58 \mathrm{mg} \mathrm{g}^{-1}$, lower than any of the optimal metal-biochar composites. The sample that best captures $\mathrm{CO}_{2}$ was $\mathrm{AlCW}(4)$, which showed a $22 \%$ improvement compared to $\mathrm{CW}(0) . \operatorname{MgCW}(.01)$ and $\mathrm{FeCW}(.1)$ showed $9 \%$ and $16 \%$ improvement, respectively. The kinetics constant $(k)$ rangeed between 15 to $29 \times 10^{-5}$ for $\mathrm{MgCW}, 16$ to $22 \times 10^{-5}$ for $\mathrm{FeCW}$ and 2.4 to $19 \times 10^{-5}$ for $\mathrm{AlCW}$. The $R^{2}$ values are above .88 for aluminum, above .93 for iron, and above .97 for magnesium.

The maximum sorption of carbon dioxide was recorded for each biochar sample. $\mathrm{AlCW}, \mathrm{MgCW}$, and $\mathrm{FeCW}$ samples each had an optimal metal concentration at which $\mathrm{CO}_{2}$ adsorption was highest. All of these adsorption values were higher than that of the unmodified biochar, $\mathrm{CW}(0)$; however, AlCW samples, in general, had the highest adsorption. The $\mathrm{CO}_{2}$ capture capacity of $\mathrm{AlCW}(4)$ is comparable other adsorbing composites that are considered for large-scale applications (Table S1, Supporting Information). 


\subsection{Governing Mechanisms}

The adsorption of $\mathrm{CO}_{2}$ onto the each biochar composite was all highly reversible (Figure S2, Supporting Information). The representative AlCW sample had the highest percent regeneration of $\mathrm{CO}_{2}(99 \%)$; whereas, $\mathrm{MgCW}(.01)$ had $96 \%$ and $\mathrm{FeCW}(.1)$ had the lowest regeneration of $\mathrm{CO}_{2}(90 \%)$. These results suggested that physical adsorption could be the main mechanism governing the capture of $\mathrm{CO}_{2}$. Easy regeneration is an advantage of the biochar/metal oxydyroxide composites in the real-world applications for $\mathrm{CO}_{2}$ capture. In the case of physical adsorption, it is important to have both high surface area and abundant adsorption sites to enable surface bonding.

Figure 4 demonstrates that the adsorption of carbon dioxide onto aluminum oxide modified biochar was poorly correlated to surface area $\left(R^{2}=0.08\right)$, indicating that large surface area of the adsorbent may not guarantee the high adsorption of $\mathrm{CO}_{2}$. Figure 5 shows that, for AlCW samples, as the concentration of aluminum increased, the adsorption of $\mathrm{CO}_{2}$ increased as well, confirming that the metal oxyhydroxides played an important role in the $\mathrm{CO}_{2}$ capture. Pierre-Louis et al [29] reported that $\mathrm{AlOOH}$ particles have strong sorption ability to $\mathrm{CO}_{2}$, which is mainly controlled by surface adsorption process.

Galinsky et al. [30] found iron oxides incorporated in conductive membrane has excellent redox ability to capture $\mathrm{CO}_{2}$, under high temperatures; however, iron oxide has not been studied extensively as a $\mathrm{CO}_{2}$ capture material at low temperatures. In this work, nanosized $\mathrm{Fe}_{2} \mathrm{O}_{3}$ particles may contribute to the enhanced $\mathrm{CO}_{2}$ capture by some of the FeCWs through surface adsorption. Although the surface area of FeCW(5) is much higher than that of the $\mathrm{AlCW}(1)$, it showed lower $\mathrm{CO}_{2}$ adsorption capacity. This result 
suggests that the interactions between the $\mathrm{CO}_{2}$ and $\mathrm{AlOOH}$ particles were much stronger than that of the iron oxide particles. Further investigations, however, are still needed to understand the binding affinity between $\mathrm{CO}_{2}$ and $\mathrm{Fe}_{2} \mathrm{O}_{3}$ particles.

Only under high temperatures $\left(200-315^{\circ} \mathrm{C}\right)$ and high pressure conditions, $\mathrm{Mg}(\mathrm{OH})_{2}$ particles can chemically sorb $\mathrm{CO}_{2}$ by producing magnesium carbonate [31]. In

this work, the adsorption experiment was performed under relatively low temperature and pressure conditions, so the chemi-sorption reaction was not feasible. As the result, when the $\mathrm{Mg}(\mathrm{OH})_{2}$ particles were incorporated into the biochar framework, it showed little effect in promoting the $\mathrm{CO}_{2}$ capture by the $\mathrm{MgCWs}$.

\section{Conclusions}

Biochar, an environmentally friendly, low-cost and sustainable adsorbent can capture substantial amounts of $\mathrm{CO}_{2}$; this study showed that, after optimization, metalbiochar composites had enhanced $\mathrm{CO}_{2}$ adsorption ability, which was better than the unmodified biochar. The aluminum hydroxide-biochar composite, $\mathrm{AlCW}(4)$, captured more $\mathrm{CO}_{2}$ than the other metal composites. The $\mathrm{CO}_{2}$ capture by the biochar-based composites was mainly controlled by the surface adsorption mechanisms with contributions from both carbon surface and metal oxyhydroxide particles. Findings from this work indicated that metal oxyhydroxide-biochar composites can be a promising framework for $\mathrm{CO}_{2}$ capture with adsorption capacity comparable to commercial, more expensive sorbents.

\section{Acknowledgments}


This research was partially supported by the NSF through Grant CBET-1054405 


\section{References}

[1] J.E. Bistline, V. Rai, The role of carbon capture technologies in greenhouse gas emissions-reduction models: A parametric study for the us power sector, Energ Policy, 38 (2010) 1177-1191.

[2] A. Padurean, C.C. Cormos, P.S. Agachi, Techno-economical evaluation of post- and pre-combustion carbon dioxide capture methods applied for an igcc power generation plant, Environmental Engineering and Management Journal, 12 (2013) 2191-2201.

[3] G. Rochelle, Amine scrubbing for co2 capture, Science, 325 (2009) 1652-1654.

[4] K. Veltman, B. Singh, E.G. Hertwich, Human and environmental impact assessment of postcombustion co2 capture focusing on emissions from amine-based scrubbing solvents to air, Environ Sci Technol, 44 (2010) 1496-1502.

[5] D.M. D'Alessandro, B. Smit, J.R. Long, Carbon dioxide capture: Prospects for new materials, Angew Chem Int Edit, 49 (2010) 6058-6082.

[6] C.H. Yu, C.H. Huang, C.S. Tan, A review of $\mathrm{co}_{2}$ capture by absorption and adsorption, Aerosol and Air Quality Research, 12 (2012) 745-769.

[7] G.L. Drisko, C. Aquino, P.H.M. Feron, R.A. Caruso, S. Harrisson, V. Luca, One-pot preparation and $\mathrm{Co}_{2}$ adsorption modeling of porous carbon, metal oxide, and hybrid beads, ACS Appl Mater Interfaces, 5 (2013) 5009-5014.

[8] J. Lehmann, A handful of carbon, Nature, 447 (2007) 143-144.

[9] S. Meyer, B. Glaser, P. Quicker, Technical, economical, and climate-related aspects of biochar production technologies: A literature review, Environ Sci Technol, 45 (2011) 9473-9483. 
[10] J. Lehmann, M.C. Rillig, J. Thies, C.A. Masiello, W.C. Hockaday, D. Crowley, Biochar effects on soil biota - a review, Soil Biol Biochem, 43 (2011) 1812-1836.

[11] A. Mohd, W.A.W.A. Ghani, N.Z. Resitanim, L. Sanyang, A review: Carbon dioxide capture: Biomass-derived-biochar and its applications, J Disper Sci Technol, 34 (2013) 974-984.

[12] S.P. Sohi, Carbon storage with benefits, Science, 338 (2012) 1034-1035.

[13] A.R. Zimmerman, B. Gao, M.Y. Ahn, Positive and negative carbon mineralization priming effects among a variety of biochar-amended soils, Soil Biol Biochem, 43 (2011) 1169-1179.

[14] A.E. Creamer, B. Gao, M. Zhang, Carbon dioxide capture using biochar produced from sugarcane bagasse and hickory wood, Chem Eng J, 249 (2014) 174-179. [15] Y. Yao, B. Gao, J. Fang, M. Zhang, H. Chen, Y. Zhou, A. Creamer, Y. Sun, L. Yang, Characterization and environmental applications of clay-biochar composites, Chem Eng J, 242 (2014) 136-143.

[16] Y. Xue, B. Gao, Y. Yao, M. Inyang, M. Zhang, A.R. Zimmerman, K.S. Ro, Hydrogen peroxide modification enhances the ability of biochar (hydrochar) produced from hydrothermal carbonization of peanut hull to remove aqueous heavy metals: Batch and column tests, Chem Eng J, 200 (2012) 673-680.

[17] Y.M. Zhou, B. Gao, A.R. Zimmerman, J. Fang, Y.N. Sun, X.D. Cao, Sorption of heavy metals on chitosan-modified biochars and its biological effects, Chem Eng J, 231 (2013) 512-518. 
[18] M. Zhang, B. Gao, Y. Yao, Y.W. Xue, M. Inyang, Synthesis of porous mgo-biochar nanocomposites for removal of phosphate and nitrate from aqueous solutions, Chem Eng J, 210 (2012) 26-32.

[19] Y. Yao, B. Gao, J.J. Chen, M. Zhang, M. Inyang, Y.C. Li, A. Alva, L.Y. Yang, Engineered carbon (biochar) prepared by direct pyrolysis of mg-accumulated tomato tissues: Characterization and phosphate removal potential, Bioresource Technol, 138 (2013) 8-13.

[20] M. Zhang, B. Gao, Removal of arsenic, methylene blue, and phosphate by biochar/alooh nanocomposite, Chem Eng J, 226 (2013) 286-292.

[21] Y.P. Chang, Y.C. Chen, P.H. Chang, S.Y. Chen, Synthesis, characterization, and co2 adsorptive behavior of mesoporous alooh-supported layered hydroxides, Chemsuschem, 5 (2012) 1249-1257.

[22] M. Zhang, B. Gao, S. Varnoosfaderani, A. Hebard, Y. Yao, M. Inyang, Preparation and characterization of a novel magnetic biochar for arsenic removal, Bioresource Technol, 130 (2013) 457-462.

[23] S.S. Wang, B. Gao, A.R. Zimmerman, Y.C. Li, L. Ma, W.G. Harris, K.W. Migliaccio, Removal of arsenic by magnetic biochar prepared from pinewood and natural hematite, Bioresource Technol, 175 (2015) 391-395.

[24] W.J. Liu, H. Jiang, K. Tian, Y.W. Ding, H.Q. Yu, Mesoporous carbon stabilized mgo nanoparticles synthesized by pyrolysis of mgcl 2 preloaded waste biomass for highly efficient co2 capture, Environ Sci Technol, 47 (2013) 9397-9403. 
[25] M.S. Shafeeyan, W.M.A.W. Daud, A. Houshmand, A. Arami-Niya, Ammonia modification of activated carbon to enhance carbon dioxide adsorption: Effect of preoxidation, Appl Surf Sci, 257 (2011) 3936-3942.

[26] Y.C. Guo, J.F. Zhao, J.X. Xu, W. Wang, F.S. Tian, G.Y. Yang, M.P. Song, Aerobic oxidation of benzyl alcohol catalyzed by cu-mn mixed oxides and 2,2,6,6-tetramethylpiperidyl-1-oxyl, Journal of Natural Gas Chemistry, 16 (2007) 210-212.

[27] JCPDS--International Centre for Diffraction Data., American Society for Testing and Materials., Mineral powder diffraction file : Data book, International Centre for Diffraction Data, Swarthmore, PA, U.S.A. (1601 Park La., Swarthmore 19081), 1986. [28] Y. Yao, B. Gao, J.J. Chen, L.Y. Yang, Engineered biochar reclaiming phosphate from aqueous solutions: Mechanisms and potential application as a slow-release fertilizer, Environ Sci Technol, 47 (2013) 8700-8708.

[29] A.M. Pierre-Louis, D.B. Hausner, N. Bhandari, W. Li, J. Kim, J.D. Kubicki, D. Strongin, Adsorption of carbon dioxide on al/fe oxyhydroxide, J Colloid Interf Sci, 400 (2013) 1-10.

[30] N.L. Galinsky, Y. Huang, A. Shafiefarhood, F.X. Li, Iron oxide with facilitated o2transport for facile fuel oxidation and co2 capture in a chemical looping scheme, Acs Sustainable Chemistry \& Engineering, 1 (2013) 364-373.

[31] M. Bhagiyalakshmi, P. Hemalatha, M. Ganesh, P.M. Mei, H.T. Jang, A direct synthesis of mesoporous carbon supported mgo sorbent for co2 capture, Fuel, 90 (2011) $1662-1667$. 
Table 1. Summary of the basic properties of biochar-based nanocomposties

\begin{tabular}{lrrrr}
\hline & Metal ratio & $\begin{array}{l}\text { Surface Area } \\
\left(\mathrm{m}^{2} \mathrm{~g}^{-1}\right)\end{array}$ & $\begin{array}{l}\text { Pore Volume } \\
\left(\mathrm{mL} \mathrm{g}^{-1}\right)\end{array}$ & \% Metal in biochar \\
\hline $\operatorname{CW}(0)$ & 0 & 99 & 0.01 & $<0.1$ \\
$\operatorname{MgCW}(.01)$ & 0.01 & 275 & 0.01 & 0.2 \\
$\operatorname{MgCW}(.25)$ & 0.25 & 244 & 0.03 & 1.7 \\
$\operatorname{MgCW}(1)$ & 1 & 184 & 0.1 & 3.7 \\
$\operatorname{MgCW}(3)$ & 3 & 228 & 0.12 & 4.5 \\
$\operatorname{MgCW}(6)$ & 6 & 197 & 0.29 & 5.5 \\
$\operatorname{MgCW}(20)$ & 20 & 289 & 0.25 & 4.7 \\
$\operatorname{MgCW}(40)$ & 40 & 262 & 0.27 & 5.7 \\
$\operatorname{AlCW}(.025)$ & 0.03 & 256 & 0.01 & 0.1 \\
$\operatorname{AlCW}(.25)$ & 0.25 & 206 & 0.03 & 0.6 \\
$\operatorname{AlCW}(2.5)$ & 2.5 & 331 & 0.3 & 0.7 \\
$\operatorname{AlCW}(1)$ & 1 & 263 & 0.25 & 0.8 \\
$\operatorname{AlCW}(3)$ & 3 & 370 & 0.39 & 0.6 \\
$\operatorname{AlCW}(4)$ & 4 & 367 & 0.37 & 0.6 \\
$\operatorname{FeCW}(.01)$ & 0.01 & 302 & 0.01 & 0.2 \\
$\operatorname{FeCW}(.05)$ & 0.05 & $\mathrm{NA}$ & $\mathrm{NA}$ & 0.6 \\
$\operatorname{FeCW}(.1)$ & 0.1 & 458 & 0.04 & 1.1 \\
$\operatorname{FeCW}(5)$ & 5 & 665 & 0.59 & 3.3 \\
$\operatorname{FeCW}(6)$ & 6 & 654 & 0.19 & 2.1 \\
$\operatorname{FeCW}(10)$ & 10 & 749 & 0.33 & 3.7 \\
\hline
\end{tabular}


Table 2. Summary of the best-fit parameters of second-order kinetics model ${ }^{*}$ for $\mathrm{CO}_{2}$ adsorption.

\begin{tabular}{|c|c|c|c|}
\hline & $q_{e}\left(\mathrm{mg} \mathrm{g}^{-1}\right)$ & $k\left(\mathrm{~g} \mathrm{mg}^{-1} \mathrm{~s}^{-1}\right)$ & $R^{2}$ \\
\hline $\mathrm{CW}(0)$ & 57.96 & 0.00019 & 0.98 \\
\hline $\operatorname{MgCW}(.01)$ & 63.69 & 0.00015 & 0.97 \\
\hline $\operatorname{MgCW}(.25)$ & 47.69 & 0.00021 & 0.97 \\
\hline $\operatorname{MgCW}(1)$ & 35.35 & 0.00018 & 0.99 \\
\hline $\operatorname{MgCW}(3)$ & 33.83 & 0.00021 & 0.99 \\
\hline $\operatorname{MgCW}(6)$ & 27.79 & 0.00029 & 0.99 \\
\hline $\operatorname{MgCW}(20)$ & 35.05 & 0.00027 & 0.98 \\
\hline $\operatorname{MgCW}(40)$ & 32.33 & 0.00028 & 0.98 \\
\hline $\mathrm{AlCW}(.025)$ & 63.87 & 0.00015 & 0.97 \\
\hline $\operatorname{AlCW}(.25)$ & 62.98 & 0.00012 & 0.98 \\
\hline $\operatorname{AlCW}(1)$ & 69.3 & 0.000048 & 0.96 \\
\hline $\operatorname{AlCW}(2.5)$ & 64.63 & 0.000035 & 0.88 \\
\hline $\mathrm{AlCW}(3)$ & 69.49 & 0.000024 & 0.89 \\
\hline $\mathrm{AlCW}(4)$ & 71.05 & 0.000041 & 0.89 \\
\hline $\mathrm{FeCW}(.01)$ & 64.3 & 0.0002 & 0.98 \\
\hline $\operatorname{FeCW}(.05)$ & 55.61 & 0.00022 & 0.95 \\
\hline $\mathrm{FeCW}(.1)$ & 66.57 & 0.00018 & 0.98 \\
\hline $\mathrm{FeCW}(5)$ & 60.68 & 0.00017 & 0.98 \\
\hline $\mathrm{FeCW}(6)$ & 65.26 & 0.00016 & 0.98 \\
\hline $\mathrm{FeCW}(10)$ & 53.79 & 0.00021 & 0.93 \\
\hline
\end{tabular}

*: Governing equation: $\quad=(-) 2$, where is the amount of $\mathrm{CO}_{2}$ adsorbed at time $(\mathrm{sec})$ and is the amount at equilibrium $\left(\mathrm{mg} \mathrm{g}^{-1}\right) . \quad 1$ is the second order rate constant $\left(\mathrm{g} \mathrm{m}^{-1} \mathrm{~h}^{-1}\right)$. 


\section{Figure captions}

Figure 1. SEM-EDS analysis of representative biochar samples: a) $\mathrm{MgCW}$, b) $\mathrm{AlCW}$, and c) $\mathrm{FeCW}$

Figure 2. XRD analysis of representative biochar samples.

Figure 3. $\mathrm{CO}_{2}$ adsorption onto the optimal metal oxyhydroxide-biochar composites.

Figure 4. Correlation between surface area and $\mathrm{CO}_{2}$ adsorption capacity of AlCW.

Figure 5. Correlation between metal content and $\mathrm{CO}_{2}$ adsorption capacity of $\mathrm{AlCW}$. 
Figure 1.
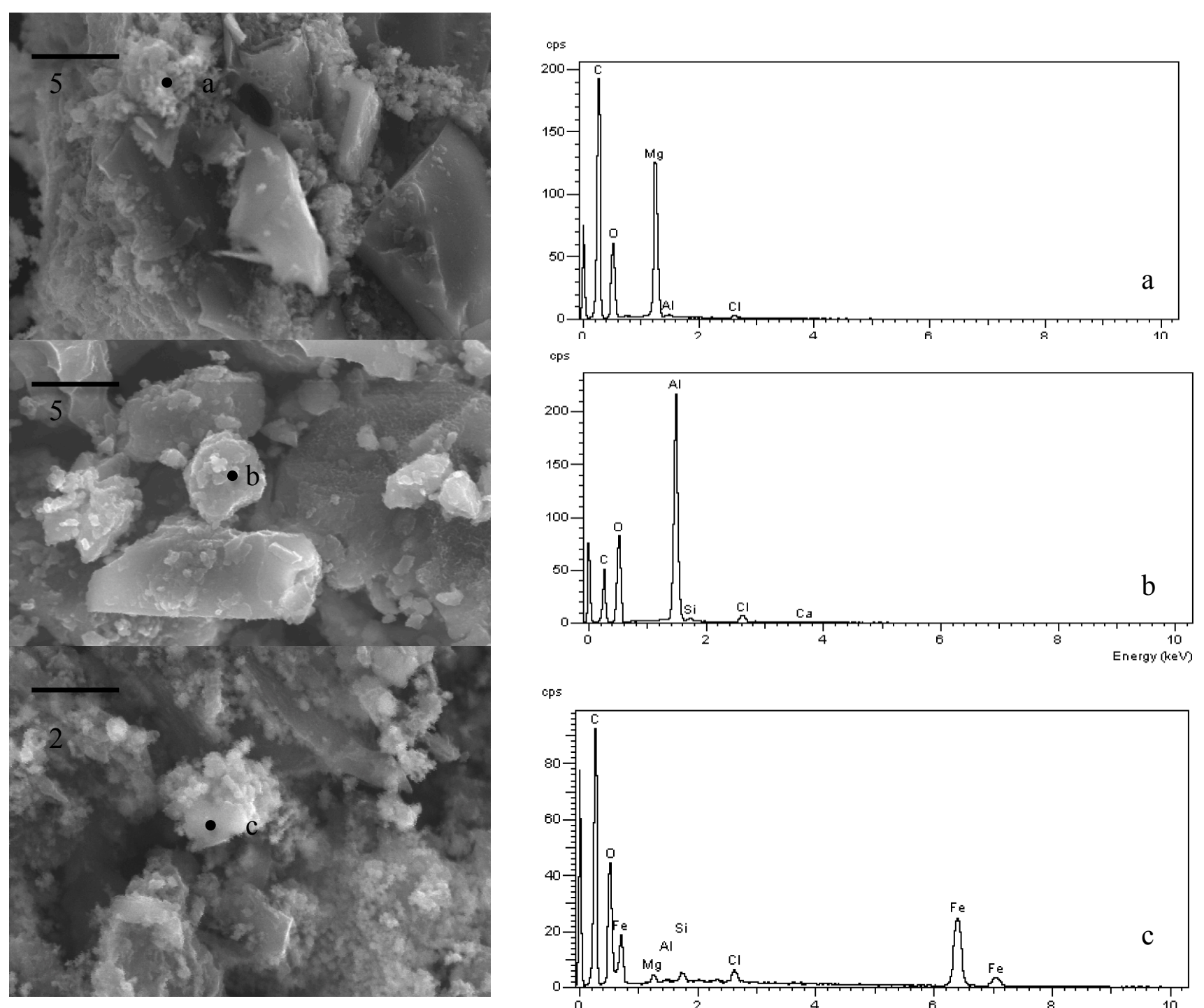

ops

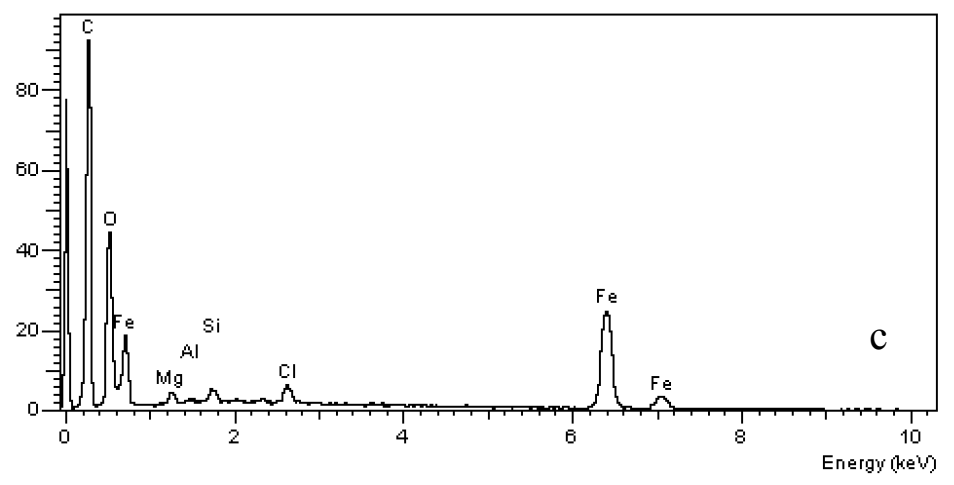


Figure 2.

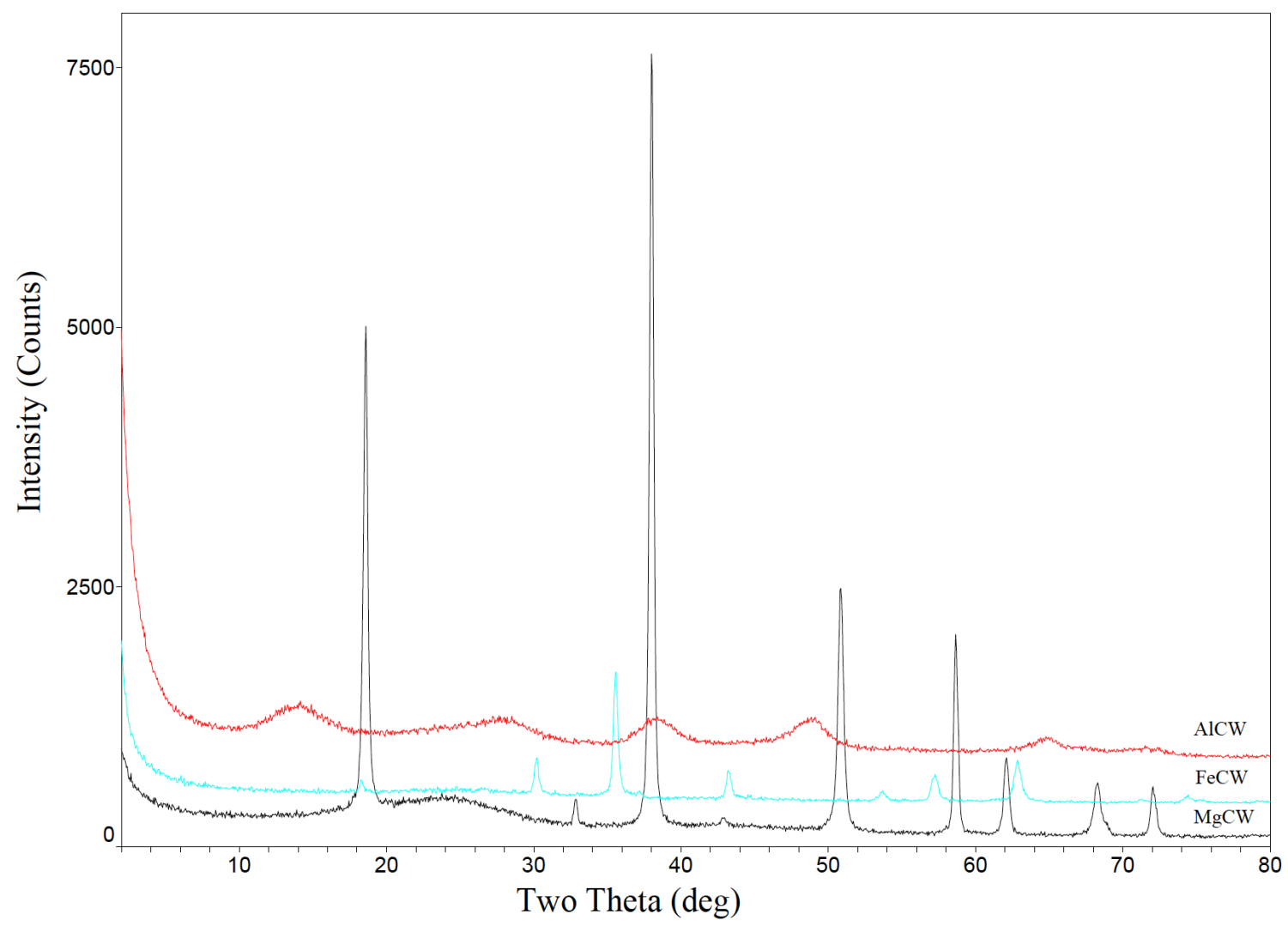




\section{Figure 3.}

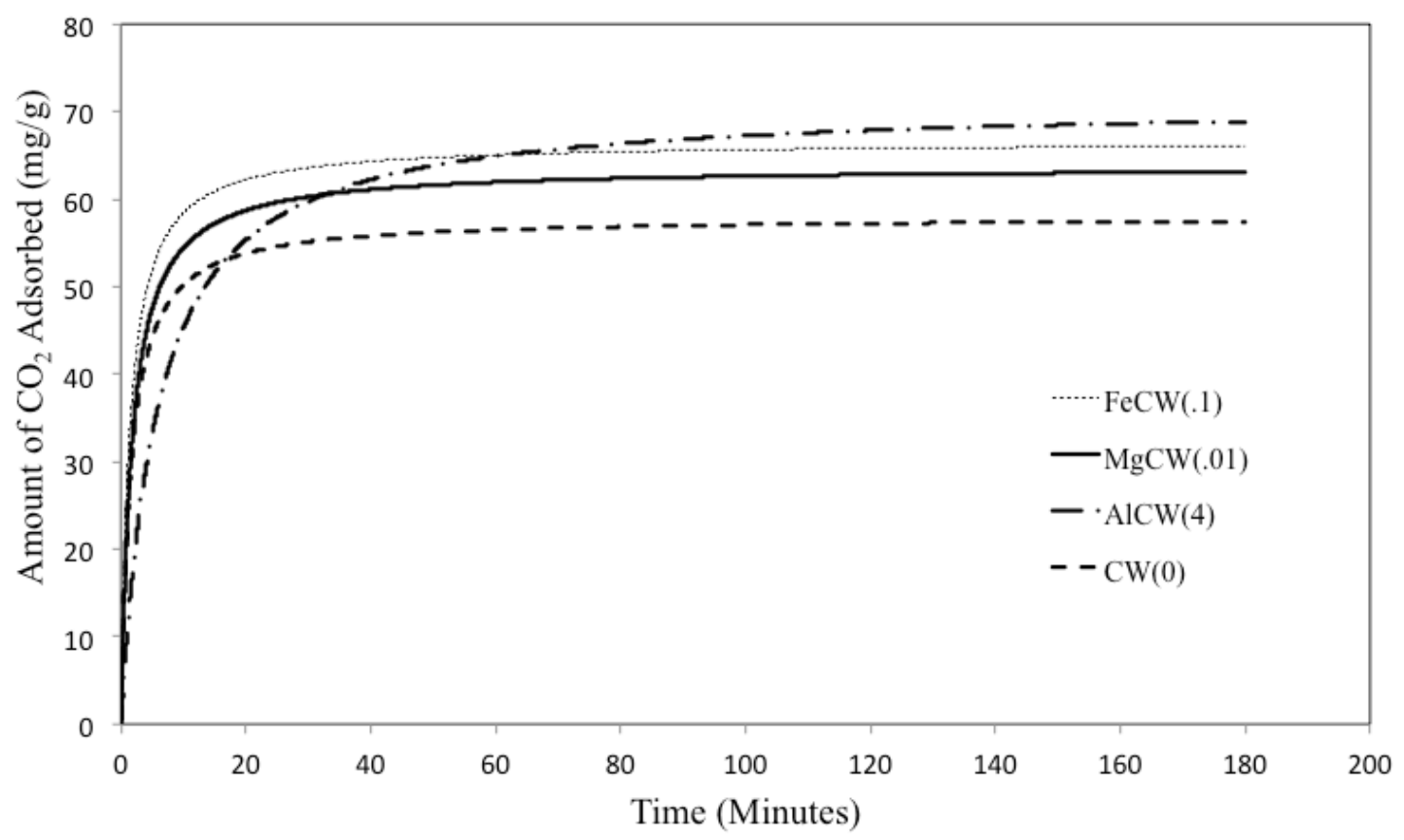


Figure 4.

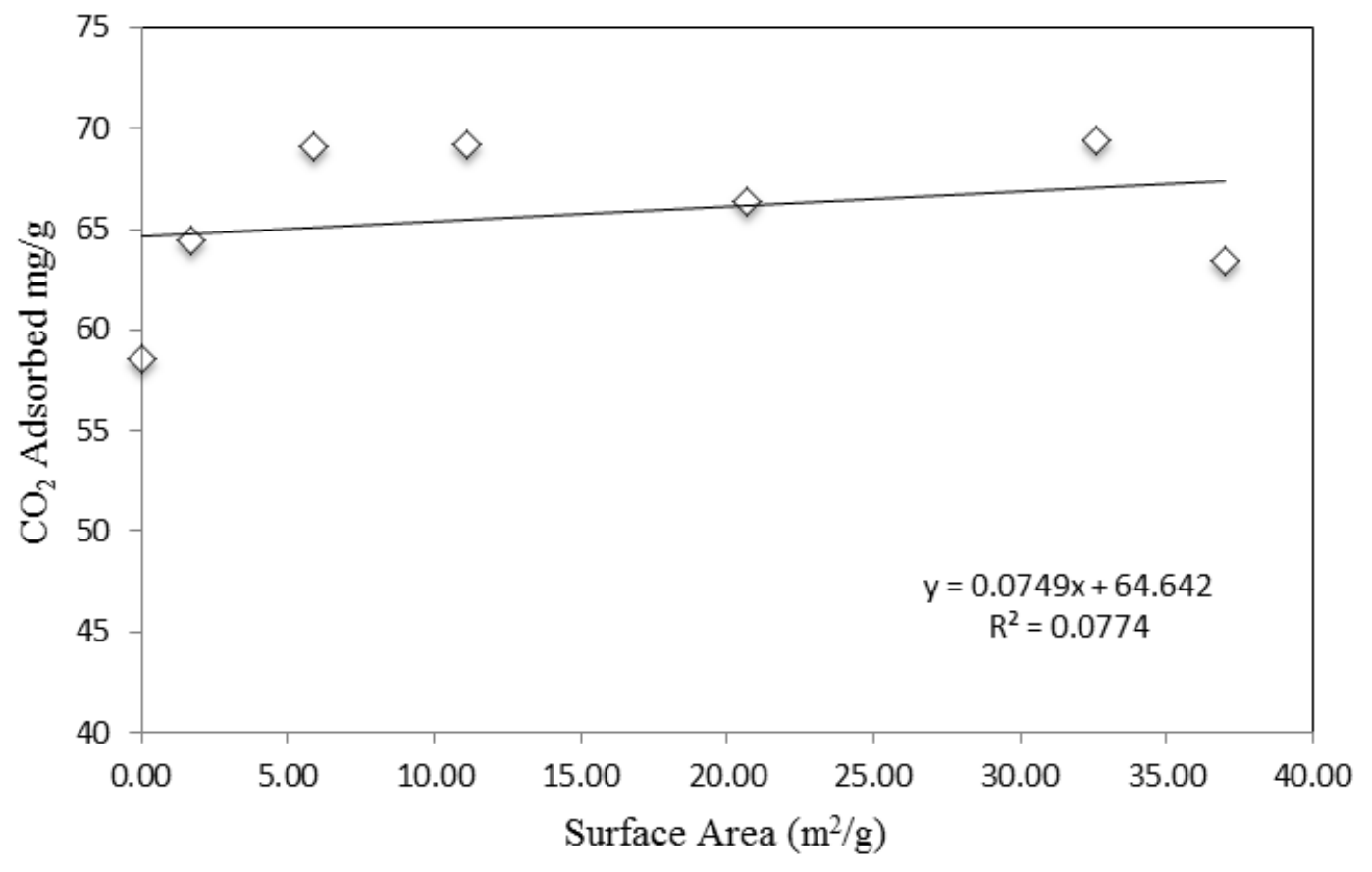


Figure 5.

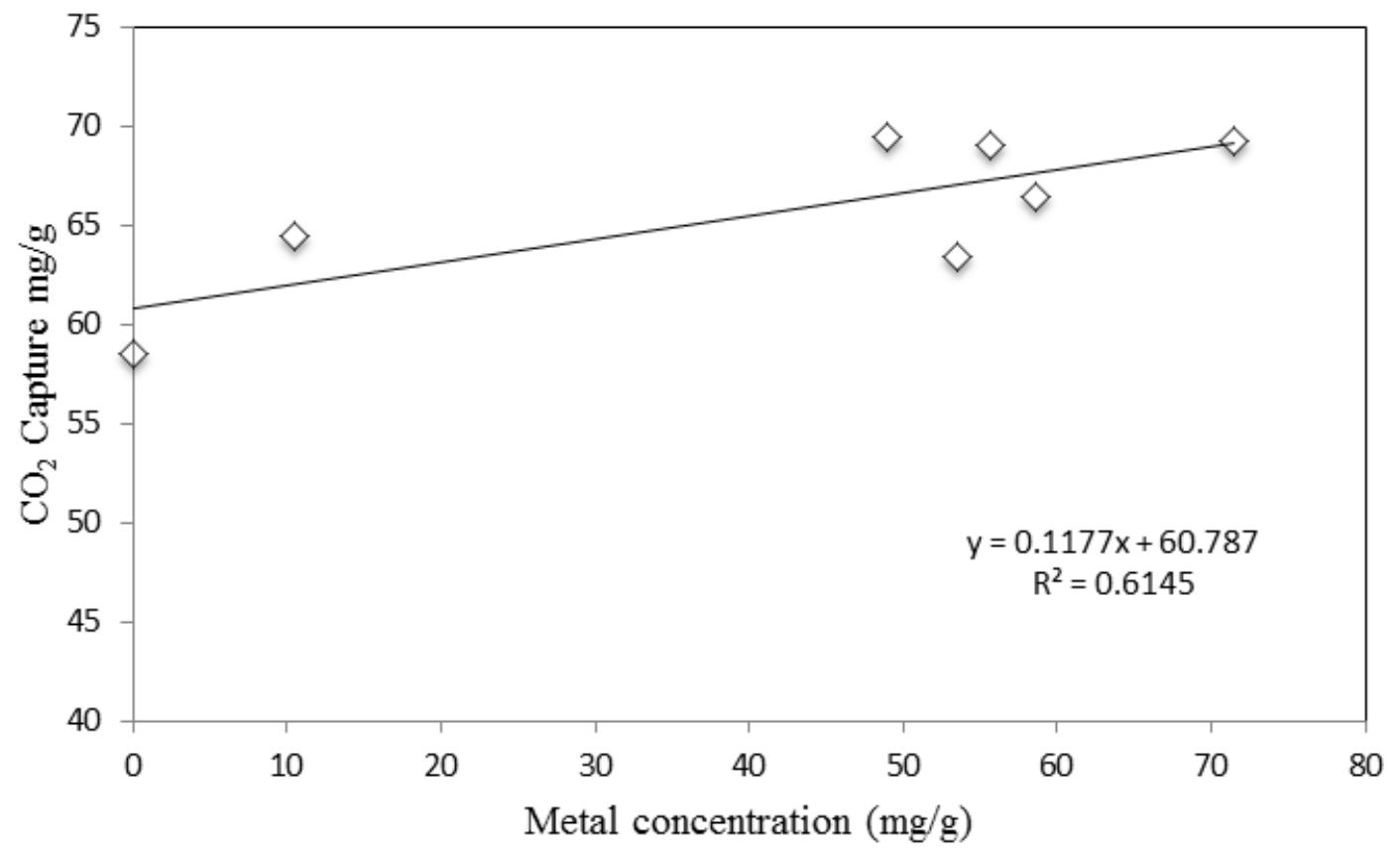

